\title{
Characterisation of eumelanin-chitosan films
}

\author{
S. Jaitrong1, P. Srisuk ${ }^{2,3,4}$, E.M. Fernandes 2,3 , V.M. Correlo ${ }^{2,3}$ and R.L. Reis ${ }^{2,3}$ \\ ${ }^{1}$ Faculty of Agricultural Technology, Burapha University, Sakaeo campus, Sakaeo, Thailand; 23B's Research Group \\ - Biomaterials, Biodegradables and Biomimetics, University of Minho, Guimarães, Portugal; 3ICVS/3B's - PT \\ Government Associate Laboratory, Braga/Guimarães, Portugal; ${ }^{4}$ Faculty of Pharmaceutical Sciences, KhonKaen \\ University, KhonKaen, Thailand.
}

\begin{abstract}
Food packaging films based on chitosan $(1 \%, w / v)$ were developed by optimising chitosan thin films with different concentrations of eumelanin $0,0.05,0.1$, 0.2 and $0.4 \%$ respectively. The properties of eumelanin-chitosan (EU-Ch) films, including colour, water contact angle, mechanical properties, degradation ratio, moisture content (MC), and total soluble matter (TSM), were investigated. The results showed that by increasing eumelanin concentrations, the colour of EU-Ch films changed from transparent to brown. Water contact angles of pure chitosan and EU-Ch films varied 94.55 to $97.49^{\circ}$, demonstrating that chitosan-based films are hydrophobic. The water contact angles remained independent of the addition of eumelanin at all tested concentrations. The EU-Ch films showed better mechanical performance in the wet state. This is an indication that water works as a plasticiser by decreasing stiffness and strength and increasing strain at break. The degradation ratio of pure chitosan films was higher than EU-Ch films with values $25 \%$ higher even after 60 days. Moisture content of pure chitosan was higher than EU-Ch films and MC values decreased when eumelanin content was increased. TSM $_{\text {dry }}$ values are lower than TSM $_{\text {wet }}$ values.
\end{abstract}

Keywords: eumelanin film, total soluble matter (TSM), water uptake, degradation, contact angle, tensile strength, TGA

\section{INTRODUCTION}

Biodegradable polymers from renewable sources provide environmentally friendly alternatives to conventional food packaging materials. Chitosan is the second most abundant polysaccharide found in nature and has non-toxic, biodegradable, and antimicrobial characteristics, which are of great interest for packaging purposes (Leceta et al., 2013). The main purpose of food packaging is to protect food from microbial and chemical contamination, water vapour and light. It has also been defined as a packaging system that actively changes the condition of the package to extend shelf life or improve food safety or sensory properties, while maintaining the quality of the food (Vermeiren et al., 1999). Melanins are biomacromolecules responsible for the pigmentation of many plants and animals (Wünsche et al., 2013). The proposed functions of melanins include photoprotection, metal ion chelation, inhibition of microbial growth, and free radical quenching. Eumelanins are ubiquitous melanin pigments and are biopolymers produced enzymatically from tyrosine via formation of 5,6-dihydroxyindole (DHI) and 5,6dihydroxyindole-2-carboxylic acid (DHICA) (Tsukamoto et al., 1992). Eumelanins are isolated from the ink sacs of the cuttlefish Sepia officinalis (Clancy and Simon, 2001). Unfortunately, the structures and exact chemical constitutions of melanins are not understood in detail. In the case of melanins, the situation is especially difficult since they are highly heterogeneous materials, to which techniques such as infrared spectroscopy or UV-VIS spectroscopy are characterised by only very broad absorption bands. The aim of this work was to prepare films based on chitosan to improve mechanical properties of the biofilms by addition of glycerol and eumelanin. This paper studied the influence of the chitosan/eumelanin ratio on the functional properties of the films, such as mechanical and barrier properties, which are relevant for food packaging applications. 


\section{MATERIALS AND METHODS}

The ink suspension of Sepia officinalis (Nortindal Sea Products S.L., Spain) was dissolved in ultrapure water, centrifuged $\left(15 \mathrm{~min}, 13,000 \mathrm{rpm}, 5^{\circ} \mathrm{C}\right.$ ) (Sigma 2-16K centrifuge) and eumelanin pellets were lyophilised for seven days. Eumelanin pellets ( $0.5 \mathrm{~g})$ were dissolved in $10 \mathrm{~mL}$ of 1-butyl-3-metylimidazolium chloride (Sigma-Aldrich, USA) and heated at $40^{\circ} \mathrm{C}$ for $20 \mathrm{~min}$. The solutions were kept at $5 \pm 1^{\circ} \mathrm{C}$ until used. Eumelanin-chitosan films were prepared by dissolving chitosan powder $(1 \%, \mathrm{w} / \mathrm{v})$ (medium molecular weight, Sigma-Aldrich, Spain) in acetic acid solution (1\%, v/v) (VWR International Ltd., UK), stirred for $1 \mathrm{~h}$ at $60 \pm 1^{\circ} \mathrm{C}$. Glycerol (Sigma-Aldrich, USA) $0.5 \mathrm{~g}$, and eumelanin $(0.05,0.1,0.2$ and $0.4 \%, \mathrm{w} / \mathrm{v}$ ) were subsequently added with continuous homogenisation. The resulting solutions were filtered and degassed, then $36 \mathrm{~g}$ poured onto glass plates, and dried at $60^{\circ} \mathrm{C}$ for $24 \mathrm{~h}$. Dried films were neutralised by $\mathrm{NaOH}$ solutions (2\%, w/v) (Sigma-Aldrich, USA) for 30 min to neutralise any residual acetic acid in the films. These films were then washed thoroughly with distilled water until the water ran neutral, dried at $60^{\circ} \mathrm{C}$ for $1 \mathrm{~h}$, and stored at room temperature.

The films were further characterised and tested. The film thickness was measured with a hand-held digital micrometer (Mitutoyo, Japan) having a sensitivity of $0.001 \mathrm{~mm}$. Colour values of films were measured using a portable colorimeter (CR-400 Minolta Chroma Meter, Japan) calibrated with a white tile, and the CIELAB colour scale was used to measure colour. Contact angle measurements were performed by the sessile drop method using a OCA 15+ contact angle meter with a high performance image processing system (DataPhysics Instruments, Germany) and the circle fit algorithm with a sessile drop of water ( $3 \mu \mathrm{L}$, HPLC grade). Tensile tests were performed on the chitosan films in the dry and wet state after $24 \mathrm{~h}$ immersed in deionised water using an Instron 5543. The uniaxial tests were carried out with a crosshead speed of $5 \mathrm{~mm} \mathrm{~min}^{-1}$ and a load cell of $1 \mathrm{kN}$. The dimension of the films was $10 \mathrm{~mm}$ width and $22 \mu \mathrm{m}$ of thickness with a gauge length of $20 \mathrm{~mm}$. Tensile modulus $(E)$ was obtained from the slope of the tangent at origin of the stress-strain curve using the linear regression method. The maximum tensile strength $\left(\sigma_{\max }\right)$ was the maximum obtained load value, normally measured at the breaking point. Thermogravimetric analyser (TGA) Q500 from TA Instruments was used for the analysis of the produced films.

Samples with round shape were heated from room temperature up to $700^{\circ} \mathrm{C}$ at $10^{\circ} \mathrm{C}$ $\mathrm{min}^{-1}$ under a constant nitrogen flow of $60 \mathrm{~mL} \mathrm{~min}^{-1}$ and their weight loss was measured. The water uptake ability of the EU-Ch films was studied by immersing them in phosphate buffer (PBS) solution ( $\mathrm{pH}=7.4$ ), at room temperature, for periods from $6 \mathrm{~h}$ to 60 days. After each time point, the wet weight of the samples was determined. The percentage of water uptake was determined: Water uptake ratio $(\%)=\left(m_{w, t}-m_{0}\right) / m_{0} * 100 \%$; where $m_{0}$ is the initial weight of the sample, and $\mathrm{m}_{\mathrm{w}, \mathrm{t}}$ is the wet weight of the samples at time after being removed from the PBS solution. After determination of the water uptake ratio, the samples were then dried at room temperature until a constant weight was reached. The percentage of degradation was calculated as follows: Degradation $(\%)=\left(m_{0}-m_{d, t}\right) / m_{0} * 100 \%$; where $m_{d, t}$ is the dry weight of the samples degraded for a certain period of time.

Moisture content of film was assessed according to Leceta et al. (2013). Three specimens of each film were weighed $\left(m_{w}\right)$ and subsequently dried in an air-circulating oven at $105^{\circ} \mathrm{C}$ for $24 \mathrm{~h}$. Films were then reweighed $\left(m_{0}\right)$, to determine their moisture content (MC): MC (\%) $=\left(m_{w}-m_{0}\right) / m_{w}$. The total soluble matter (TSM) determinations were carried out according to the "wet method" proposed by Pereda et al. (2012) with some modifications. Three specimens of film (film size, $2 \times 2 \mathrm{~cm}^{2}$ ) were weighed $\left(m_{h}\right)$ $( \pm 0.0001 \mathrm{~g})$ and then directly immersed in distilled water $(5 \mathrm{~mL})$. After $24 \mathrm{~h}$ immersion, the samples were oven dried at $105^{\circ} \mathrm{C}$ for $24 \mathrm{~h}$, to determine the dried remnant insoluble mass $\left(m_{f}\right)$. The initial dry mass values $\left(m_{0}\right)$ needed for the TSM calculations were obtained from different specimens cut from the same film and dried at $105^{\circ} \mathrm{C}$ for $24 \mathrm{~h}$. The TSM was calculated as follows: TSM $(\%)=\left(m_{0}-m_{f}\right) / m_{0} * 100 \%$. All experiments were conducted by triplicate determinations and data were subjected to analysis of variance and Tukey's multiple range test $(p \leq 0.05)$. 


\section{RESULTS AND DISCUSSION}

At macroscopic scale all films were homogenous and occurred with an approximate thickness of $22 \pm 1 \mu \mathrm{m}$. Film colour can be a factor influencing consumer acceptance; and arange of colours occurred in the EU-Ch films (Figure 1). Pure chitosan films (1\%, w/v) were transparent and acquired brown colour with the addition of eumelanin. As shown in Figure 1 , the degree of colour increased at higher concentrations of eumelanin. The $L$ value and hue angle continually decreased and chroma value gradually increased. For the EU-Ch films, the values of $\mathrm{L}$, chroma, and hue angles were significantly $(p \leq 0.05)$ influenced by eumelanin concentrations (Table 1).

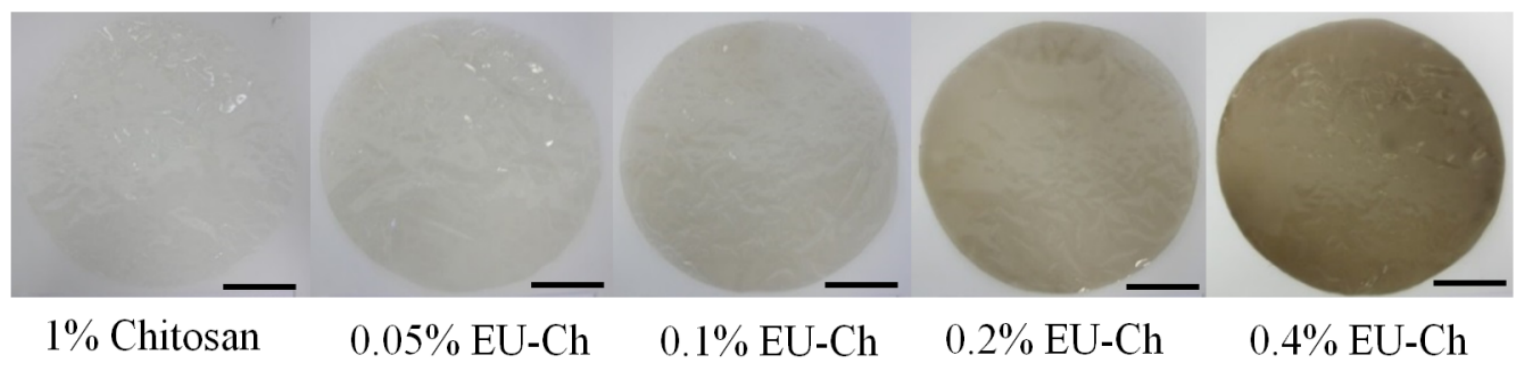

Figure 1. Appearance of eumelanin-chitosan (EU-Ch) films. Scale bar $=2.5 \mathrm{~cm}$.

Table 1. Colour $\left(\mathrm{L}^{*}, \mathrm{C}^{*}\right.$ and $\left.\mathrm{h}^{\circ}\right)$, moisture content (MC), total soluble matter (TSM) and contact angle (CA) of EU-Ch films.

\begin{tabular}{|c|c|c|c|c|c|c|c|}
\hline \multirow{2}{*}{$\begin{array}{l}\text { Eumelanin } \\
\text { conc. }(\%)\end{array}$} & \multicolumn{3}{|c|}{ Color } & \multirow{2}{*}{$\begin{array}{l}\text { MC } \\
(\%)\end{array}$} & \multirow{2}{*}{$\begin{array}{c}\text { TSM }_{\text {wet }} \\
(\%)\end{array}$} & \multirow{2}{*}{$\begin{array}{c}\mathrm{TSM}_{\text {dry }} \\
(\%)\end{array}$} & \multirow{2}{*}{ CA } \\
\hline & $L^{*}$ & $\mathrm{C}^{*}$ & $h^{\circ}$ & & & & \\
\hline 0 & $82.76 \pm 0.5^{a}$ & $3.11 \pm 0.1^{c}$ & $114.31 \pm 1.2^{\mathrm{a}}$ & $8.20 \pm 0.2^{\mathrm{a}}$ & $13.11 \pm 0.7^{a}$ & $8.25 \pm 1.4^{a}$ & $97.78 \pm 0.2^{\mathrm{a}}$ \\
\hline 0.0 & 8 & & $114.47=$ & $6.51 \pm 1.0^{\mathrm{ab}}$ & 11.21 & 8.04 & \\
\hline 0.1 & $30 \pm 1.5^{b}$ & $7.77 \pm 1.1^{b}$ & $92.70 \pm 1.4^{b}$ & $6.33 \pm 0.8^{a b}$ & $9.45 \pm 0.1^{c}$ & $7.40 \pm 1.3^{a}$ & 92.2 \\
\hline 0.2 & $71.88 \pm 0.9 c$ & $9.98 \pm 0.6^{b}$ & $86.70 \pm 1.2^{c}$ & $6.74 \pm 1.2^{a b}$ & $9.11 \pm 0.1^{c}$ & $6.99 \pm 1.1^{\mathrm{a}}$ & $94.73 \pm 1.0^{a b}$ \\
\hline 0.4 & $62.63 \pm 2.9^{d}$ & $15.32 \pm 1.6^{a}$ & $79.73 \pm 1.6^{d}$ & $4.10 \pm 1.0^{b}$ & $8.82 \pm 0.8^{c}$ & $5.30 \pm 1.4^{a}$ & $89.62 \pm 1.0^{c}$ \\
\hline
\end{tabular}

Means within the same column followed by different letters are significantly different at $95 \%(p \leq 0.05)$ level by Tukey's multiple range test. Data are mean values $\pm S D$.

Surface properties of the films (i.e., contact angle) give information about the phenomenon of wetting or non-wetting of a product surface by film forming dispersions and thus, about the uniformity of coating when applied to a product. Moreover, the contact angle testing is a simple way to determine the superficial hydrophilicity of films since, when using water or another polar solvent, contact angle will increase with increasing surface hydrophobicity (Hambleton et al., 2009; Pereda et al., 2010; Zia et al., 2010). In general, the quantitative differentiation between "hydrophobic" and "hydrophillic" surface is based on whether $\theta>65^{\circ}$ or $\theta<65^{\circ}$, respectively (Vogler, 1998). Contact angles of pure chitosan with different contents of eumelanin varied between 94.55 to $97.49^{\circ}$ (Table 1). These results are in agreement with the hydrophobic character of chitosan-based film and, independently of the concentration, the addition of eumelanin didn't change its character.

Tensile strength indicates the maximum tensile stress that the film can sustain, where the strain is the maximum change in length of a test specimen before breaking. Tensile modulus is a measure of the stiffness of the film. Mechanical properties of films are largely associated with the distributions and densities of intermolecular and intramolecular interactions in the network created in EU-Ch films. As expected, all films showed better mechanical performance in the wet state. For dry state, tensile strength increased with higher eumelanin content. The flexibility of the film was estimated by measuring the percent elongation (E) value found to be influenced by the eumelanin content in wet state. The average $E$ value of the films increased with moisture from 37 to $50 \%$ (Figure 2). This is an indication that water functions as a plasticiser by decreasing stiffness and strength and 
increasing strain at break. Incorporation of eumelanin into chitosan films increased tensile strength and tensile modulus in the dry state. A strong interaction between the polymer and the eumelanin decreases the free volume and the molecular mobility of the polymer (Pereda et al., 2012).
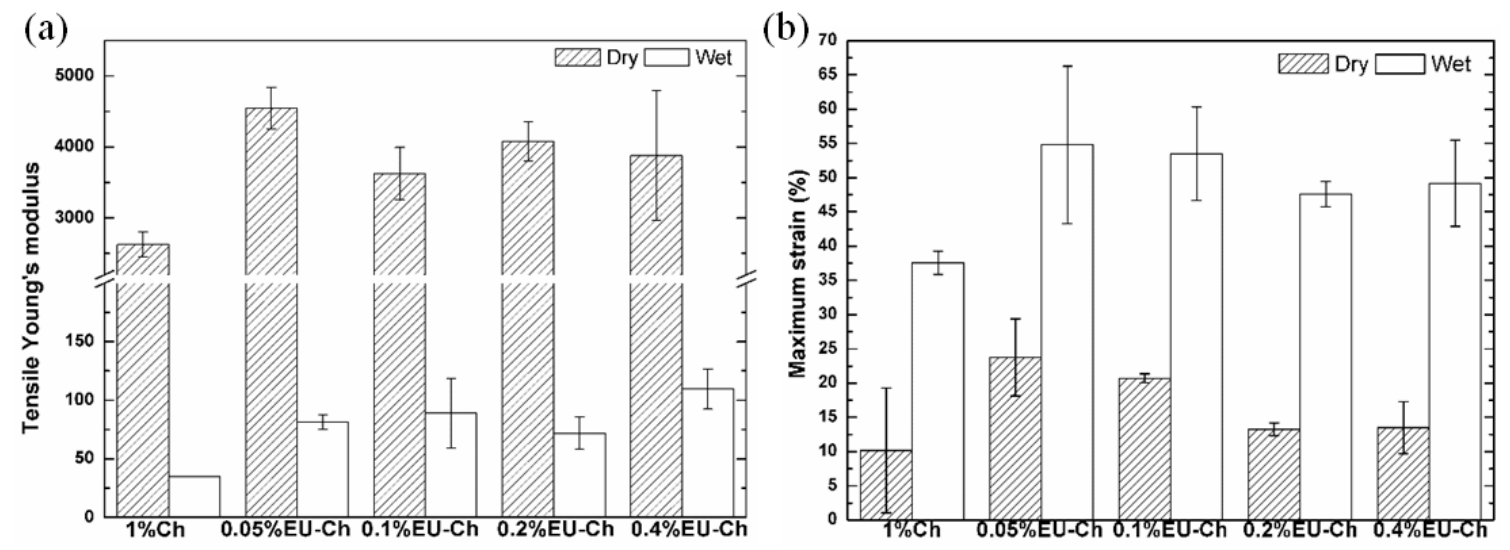

Figure 2. Mechanical properties of EU-Ch films. Tensile Young's modulus (a) and maximum strain (b).

Other important characteristics of the EU-Ch films are their high thermal stabilities, measured by thermogravimetric analysis (TGA) and derivative thermogravimetric analysis (DTG) (Figure 3). As polymer processing frequently involves melting and extrusion, studies of the thermal properties and other stability factors are important to technological applications of polymers. Chitosan as well as their derivatives have good film forming properties and can be processed as membranes, solutions, gels, pastes and nanoparticles (Ujang et al., 2011).The water uptake profiles of EU-Ch thin films were analysed with PBS solutions. It was observed that the water uptake ratio of the films remained stable for one month and slightly increased at the end. The differences in water uptake of each sample can be attributed to the different concentration of the eumelanin in the film. In addition, the degradation ratio of EU-Ch film slightly increased from the beginning until 60 days (data not shown).
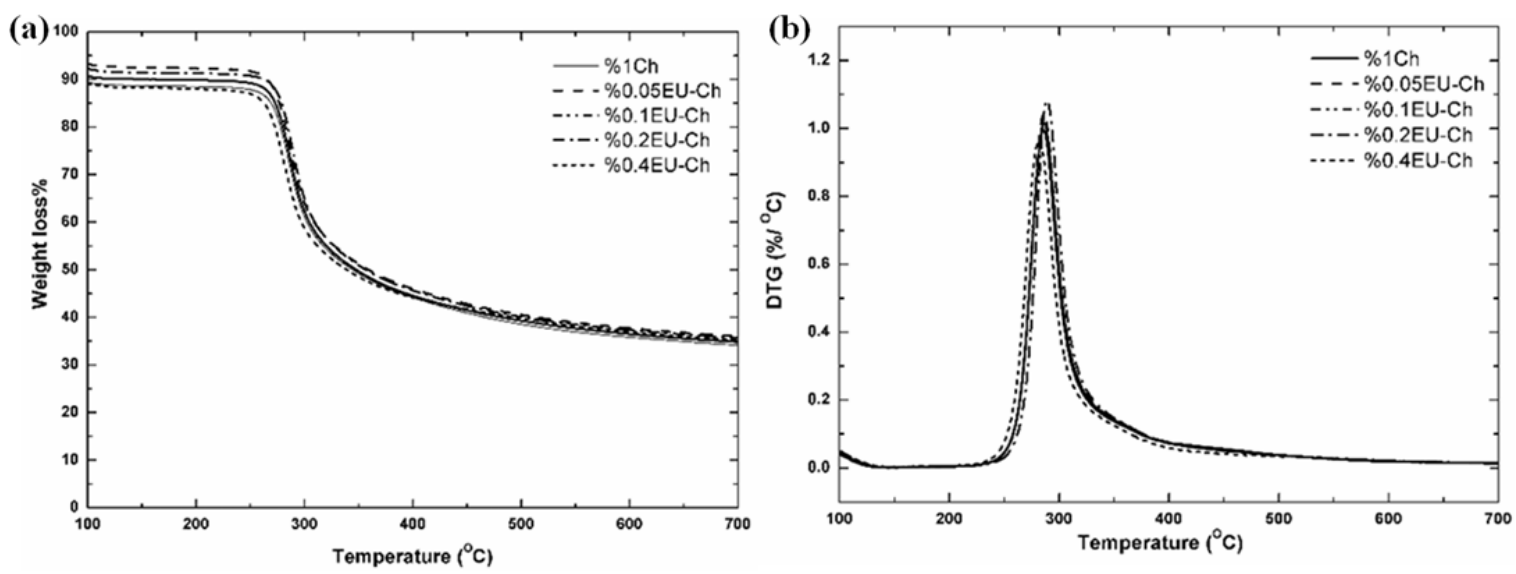

Figure 3. Thermogravimetry analysis (TGA) (a) and derivative thermogravimetric analysis (DTG) (b) of EU-Ch films.

In a comparison of five different concentration of eumelanin, the control film $(1 \%$ chitosan without eumelanin) exhibited the highest degradation with values of $25 \%$, even after 60 days. Packaging films should maintain moisture levels within the packaged product. 
Therefore, the knowledge of moisture content and total soluble matter of the films is very important for food and packaging applications. Table 1 shows MC values of chitosan without eumelanin, being around $8 \%$ and MC values decreased significantly ( $\mathrm{p} \leq 0.05$ ) when eumelanin content was increased. On the other hand, the TSM $_{\text {dry }}$ values were lower than $\mathrm{TSM}_{\text {wet }}$ values, $8.25 \pm 1.4$ and $13.11 \pm 0.7 \%$ for the chitosan-plasticised film (without eumelanin), respectively. TSM continually decreased with an increase in the eumelanin concentration.

\section{CONCLUSION}

The results of this work show that functional properties of chitosan-based films are adequate for packaging purpose. Chitosan-based films are transparent and acquire brown colour with the addition of eumelanin. Moreover, the addition of eumelanin improves film flexibility with a slightly increased hydrophobic character of the films. These results provide insights in to modes of action for the different components of the chitosan films and identify impacts of the use of the different active materials.

\section{ACKNOWLEDGEMENTS}

Financial support from the One More Step Project, Erasmus Mundus ProgrammeAction 2, to perform a mobility period at Post-Doctorate level, during the academic year 2013/2014 and 3B's Research Group, University of Minho, Portugal is acknowledged. The authors would like to thank Dr. John Manthey (Agricultural Research Service, U.S. Department of Agriculture, Ft. Pierce, FL) for reviewing the manuscript.

\section{Literature cited}

Clancy, C.M.R., and Simon, J.D. (2001). Ultrastructural organization of eumelanin from Sepia officinalis measured by atomic force microscopy. Biochemistry 40 (44), 13353-13360 https://doi.org/10.1021/bi010786t. PubMed

Hambleton, A., Fabra, M.J., Debeaufort, F., Dury-Brun, C., and Voilley, A. (2009). Interface and aroma barrier properties of iota-carrageenan emulsion-based films used for encapsulation of active food compounds. J. Food Eng. 93 (1), 80-88 https://doi.org/10.1016/j.jfoodeng.2009.01.001.

Leceta, I., Guerrero, P., and de la Caba, K. (2013). Functional properties of chitosan-based films. Carbohydr Polym 93 (1), 339-346 https://doi.org/10.1016/j.carbpol.2012.04.031. PubMed

Pereda, M., Aranguren, M.I., and Marcovich, N.E. (2010). Caseinate films modified with tungoil. Food Hydrocoll. 24 (8), 800-808 https://doi.org/10.1016/j.foodhyd.2010.04.007.

Pereda, M., Amica, G., and Marcovich, N.E. (2012). Development and characterization of edible chitosan/olove oil emulsion films. Carbohydr. Polym. 87 (2), 1318-1325 https://doi.org/10.1016/j.carbpol.2011.09.019.

Tsukamoto, K., Palumbo, A., D’Ischia, M., Hearing, V.J., and Prota, G. (1992). 5,6-Dihydroxyindole-2-carboxylic acid is incorporated in mammalian melanin. Biochem. J. 286 (2), 491-495 https://doi.org/10.1042/bj2860491. PubMed

Ujang, Z., Diah, M., Rashid, A.H.A., and Halim, A.S. (2011). The development, characterization and application of water soluble chitosan. In Biotechnology of Biopolymers, M. Elnashar, ed. (Rijeka: InTech), p.100-130.

Vermeiren, L., Devlieghere, F., van Beest, M., de Kruijf, N., and Debevere, J. (1999). Developments in the active packaging of foods. Trends Food Sci. Technol. 10 (3), 77-86 https://doi.org/10.1016/S0924-2244(99)00032-1.

Vogler, E.A. (1998). Structure and reactivity of water at biomaterial surfaces. Adv Colloid Interface Sci 74 (1-3), 69-117 https://doi.org/10.1016/S0001-8686(97)00040-7. PubMed

Wünsche, J., Cicoira, F., Graeff, C.F.O., and Santato, C. (2013). Eumelanin thin films: solution-processing, growth, and charge transport properties. J. Mater. Chem. B 1 (31), 3836-3842 https://doi.org/10.1039/c3tb20630k.

Zia, K.M., Zuber, M., Mahboob, S., Sultana, T., and Sultana, S. (2010). Surface characteristics of UV-irradiated chitin-based shape memory polyurethanes. Carbohydr. Polym. 80 (1), 229-234 https://doi.org/10.1016/ j.carbpol.2009.11.015. 
